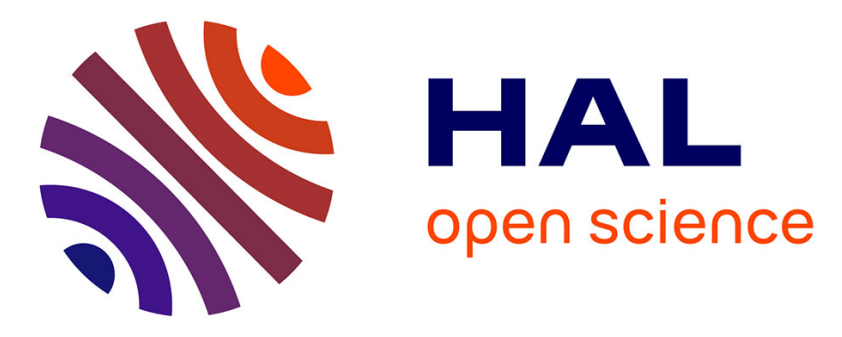

\title{
Simulation for designing industrial cobotic systems
}

Théo Moulières-Seban, David Bitonneau, Jean-François Thibault, Jean-Marc

Salotti, Bernard Claverie

\section{To cite this version:}

Théo Moulières-Seban, David Bitonneau, Jean-François Thibault, Jean-Marc Salotti, Bernard Claverie. Simulation for designing industrial cobotic systems. 30th International Seminar on Ergonomics, May 2017, Tarmow, Poland. 10.21008/j.0239-9415.2016.072.01 . hal-01670161

\section{HAL Id: hal-01670161 https://hal.science/hal-01670161}

Submitted on 21 Dec 2017

HAL is a multi-disciplinary open access archive for the deposit and dissemination of scientific research documents, whether they are published or not. The documents may come from teaching and research institutions in France or abroad, or from public or private research centers.
L'archive ouverte pluridisciplinaire HAL, est destinée au dépôt et à la diffusion de documents scientifiques de niveau recherche, publiés ou non, émanant des établissements d'enseignement et de recherche français ou étrangers, des laboratoires publics ou privés. 


\section{Article ISET 2017 Simulation for designing industrial cobotic systems}

Conference Paper · December 2017

DOI: $10.21008 / \mathrm{j} .0239-9415.2016 .072 .01$

CITATIONS

0

5 authors, including:

Théo Moulières-Seban

Université Bordeaux 1

4 PUBLICATIONS 2 CITATIONS

SEE PROFILE

\section{Jean-Marc Salotti}

Bordeaux Institut National Polytechnique 86 PUBLICATIONS 288 CITATIONS

SEE PROFILE
READS

21

Jean-François Thibault

SAFRAN GROUP

27 PUBLICATIONS 48 CITATIONS

SEE PROFILE

Some of the authors of this publication are also working on these related projects:

Project Human enhancement View project 


\begin{tabular}{lcrr} 
Z E S Z Y T Y & N A U K O W E & P O L I T E C H N I K I & P O Z N A N S K I E J \\
\hline Nr 72 & Organizacja i Zarządzanie & 2017
\end{tabular}

\author{
Théo Moulières-Seban ${ }^{1,3}$, David Bitonneau ${ }^{2,3}$, Jean-François Thibault ${ }^{2}$, \\ Jean-Marc Salotti ${ }^{3}$, Bernard Claverie ${ }^{3}$
}

\title{
SIMULATION FOR DESIGNING INDUSTRIAL COBOTIC SYSTEMS
}

DOI: $10.21008 / \mathrm{j} .0239-9415.2016 .072 .01$

\begin{abstract}
Cobotics refers to the design, production, study, and use of work systems in which one or more operator(s) interact(s) with one or more robot(s) in a shared space or remotely. This type of system is increasingly present in industry. It aims to improve how things are produced in terms of performance and health/safety by drawing on the respective strengths of operators and robots. Cobotic systems (comprising the operator, robot and task/environment) cannot be designed and put into service without anticipating difficulties related to technical complexity, the use of the system, and the industrial process. With this in mind, this article proposes to design systems based on simulations using a interdisciplinary approach drawing on ergonomics, robotics and cognitive engineering.
\end{abstract}

Keywords: Human-Centered Design, Human-Robot Interaction

\section{INTRODUCTION}

Cobotics refers to the design, production, study, and use of work systems in which one or more operator(s) interact(s) with one or more robot(s) in a shared space or at distance (Claverie, et al., 2013). This type of system is increasingly present in industry. It aims to ensure production-line flexibility, improve performance, reduce occupational illnesses and accidents and guarantee the employability of expert operators. To achieve this, we must take advantage of the complementary qualities of humans (flexibility, decision-making, expertise) robots (strength, endurance, speed, precision, repeatability).

\footnotetext{
1 Airbus Safran Launchers, 92130 Issy les Moulineaux, France

2 Safran, 92130 Issy-les-Moulineaux, France

${ }^{3}$ IMS, Univ. Bordeaux, 33405 Talence, France

(email: theo.moulieres-seban@u-bordeaux.fr, david.bitonneau@u-bordeaux.fr)
} 
T. Moulières-Seban, D. Bitonneau, J.-F. Thibault, J.-M. Salotti, B. Claverie

To facilitate the deployment of cobotic systems (comprising the operator, the robot and the task/environment) at workstations, an interdisciplinary approach drawing on ergonomics, robotics and cognitive engineering has been implemented at Safran and Airbus Safran Launchers (Moulières-Seban, et al., 2016a; 2016b). The first stage of this approach involves analyzing the operators' activity and the technical constraints at the current workstation and/or in reference situations similar to those ultimately targeted (e.g. situations already using similar cobots). Then, the request is reformulated and the need described in detail in a functional analysis drafted by the project stakeholders. The working group then discusses the general design options with the input of potential suppliers, in order to ensure their reliability. This is followed by the study stages that will contribute to the system design and determine its feasibility (see Erreur ! Source du renvoi introuvable.).

During the design (general design options and studies), the simulation is essentially used to establish a forecast of what working with the future installation will be like, in terms of its efficiency, the procedures, and the health and safety of operators. The simulation can also be used to identify needs and initiate operator training (Daniellou F. , 2004). The aim of the simulation is not to decide the best way of carrying out the tasks, but to estimate potential future types of activity with the planned system and to check if they are ergonomically acceptable (Daniellou F. , 2007a). It makes it possible to check that the planned solution meets the operators' needs, and the constraints linked to the workstation, the work organization and the process. At the same time, simulations allow to make assessments of technical feasibility. In view of the complexity of human-robot interactions, this approach requires skills in robotics, cognitive engineering and ergonomics (MoulièresSeban, et al., 2016b). 


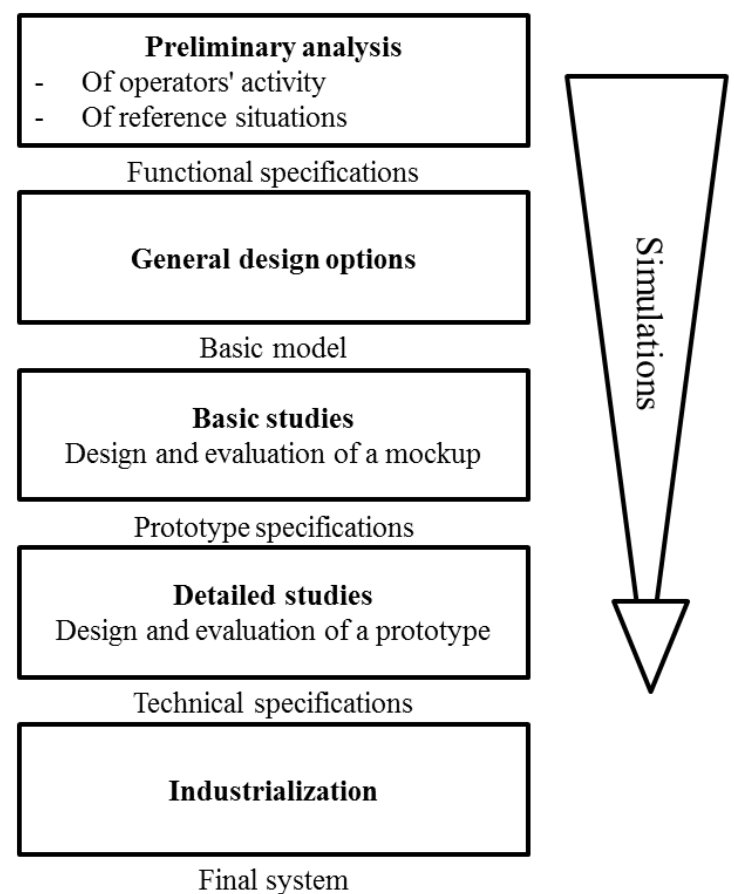

Fig. 1. Diagram of the stages of an industrial project.

In this article, we will look at the importance of simulations in industrial cobotic projects, before giving a detailed description of a tangible example of a simulation with a user test implemented at Airbus Safran Launchers.

\section{COBOTICS AND SIMULATION}

\subsection{Simulation serving design}

Below, the simulation approach is presented sequentially. Nonetheless, an approach based on simulations is part of a loop that includes:

- A top-down approach aimed at clearly defining the project objectives, thanks to interaction with the people involved in the design process, and drawing on their knowledge;

- A bottom-up approach for analyzing the operators' activity in reference situations and building scenarios concerning the future activity.

This dual top-down/bottom-up approach provides information to feed into the simulation process. It also makes it possible to progressively validate the working hypotheses (Garrigou, et al., 2001). 
T. Moulières-Seban, D. Bitonneau, J.-F. Thibault, J.-M. Salotti, B. Claverie

The first stage involves establishing the group of participants (operators, foreman, decision-maker, maintenance officers, etc.). The operators are sometimes physically absent from the actual simulation, whether they are modeled or not. Human centered design approach makes them participate actively in the simulation (Boy, 2013). In robotics, designers usually model operators in their simulations using digital models. These models can include bio-mechanical parameters (angles and efforts, for example), and even perceptual factors, such as representations of the operators' fields of vision (Daniellou F. , 2007b). However, this type of modeling induces a significant bias because the digital model behaves in the way the designers imagined the operator would/should behave. It does not incorporate the behavior of an operator who consciously and subconsciously adapts to variables that the designers are generally unaware of. Thus, for all these reasons, the "real" involvement of the operators in the simulation processes is decisive for the project.

Then, hypotheses and scenarios concerning the use of the future system are established. They are based directly on the earlier analysis of the existing system, while following certain rules (Daniellou F. , 2004):

- Chronological continuity: a tool does not just appear in an operator's hand, he must have found it somewhere.

- Cognitive continuity: e.g. how does the operator know something, how does he see, etc.

- Consideration of the operator's capabilities: e.g. the operator cannot cross the workshop while retaining 50 numerical values in his head, and he cannot lift $100 \mathrm{~kg}$.

The hypotheses can address the integration of human factors, for example by simulating acceptability, errors made during simulated interactions, the workload (physical and cognitive) or situational awareness (Drury, et al., 2003). Simulations also provide an opportunity to test hypotheses regarding the "robotic" aspects. These hypotheses can range from the sizing of the robotic system to its detailed development, such as how the robot is to be fixed (to the floor, wall, etc.), the feasibility of the movements required to complete the task, or the integration of the various technological modules. Finally, the hypotheses can also concern the industrial process, which may undergo changes at the same time as the cobotization of the workstation.

The scenarios can then be built on the basis of these hypotheses. Insofar as possible, they must take into account the variables the operator will potentially be faced with, and all the operating modes of the future installation (Thibault, 1998): normal, transitory and in case of failure. Finally, great attention must be paid to this stage to take into account the different modes of operator-robot interaction (see Table 1).

Master: the operator uses local or remote control to operate the "slave" robot, which has a little or no autonomy. This type of interaction is sometimes used to teach a robot a particular task on 
Simulation for designing industrial cobotic systems

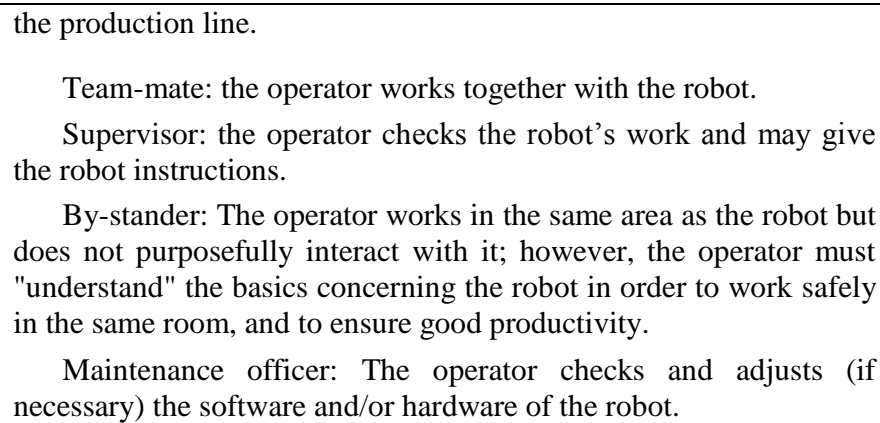

Table 1. Roles of operator during human robot interaction based on Drury et al. (2003)

Once the scenarios and hypotheses have been prepared, the design and production of the simulation materials can begin. The materials vary greatly according to the project phase (see 2.2) and according to the human-robot interaction you want to simulate. The simulation materials can range from plans/sketches to prototypes and models (Thibault, 1998). The plans and models may be digital or physical (e.g. drawings or cardboard models). The level of detail depends on the compromise between representativeness and implementation time, in order to meet the objectives described above in the most effective way, and make any design modifications as simple as possible (ISO 9241-210, 2010).

In addition, new virtual and/or augmented reality tools enable users to be immersed in the future work situation. These tools are now used to evaluate humanrobot interactions (Weistroffer, et al., 2014).

During the simulation, different measurement systems can be set up to provide answers to the hypotheses formulated:

- Subjective tools: questionnaires (before and after the test); oral or written statements from the subject; observations about the subject (behavior, reactions, strategies, etc.);

- Objective tools: performance measurements (for a task: duration, errors, quality, etc.); physiological measurements (heart rate, skin conductivity, pupil dilation, EEG, fMRI, etc.); measurement of the subject's behavior (eye-tracking, motion capture, etc.).

In human-robot interaction, physiological measurements give information about the subject's condition, i.e. stress, cognitive load or fatigue, for example. This makes it possible to note trends concerning the acceptability of the situation for users. In order to evaluate the interactions during a simulation (Olsen \& Goodrich, 2003), you can also use general usability criteria, such as Scapin and Bastien criteria (1997) or Nielsen's criteria (1990) for example.

The results of the simulations make it possible to validate/reject the hypotheses established at the start and also provide a lot of additional data gathered when the people concerned are placed in a simulation environment (concerning the planned process or future task, for example). Consequently, simulations are a useful tool to 
T. Moulières-Seban, D. Bitonneau, J.-F. Thibault, J.-M. Salotti, B. Claverie

accompany change because the users buy into the future system and will more likely accept it thanks to their proactive involvement in the industrial project.

\subsection{Simulations according to the different project phases}

During an industrial project, simulations provide decisive information at each different phase of the project (Thibault, 1998; Barcellini, et al., 2014), particularly when the project concerns cobotics. Indeed, operators can find out about new technical systems while bringing their expertise and participating in the design.

Theoretical solutions: Following the preliminary analysis and initial discussions with potential suppliers, the working group comes up with one or more potential solutions. To evaluate the solutions and ensure all the stakeholders understand them in the same way, it is very useful to have a simulation that is quick to implement. For example, it may be based on story-telling, diagrams or sketches, or a basic 3D digital animation. Note that a 3D animation can have a "marketing" aspect to help convince decision-makers.

Basic studies and model: Once the potential solution has been validated, the basic studies can begin. This stage makes it possible to fine-tune the design, notably using a model tested by the future users. Here, the model is a non-functional physical or digital reproduction of the future work system. Consequently, it provides new information concerning the technical feasibility, the human-robot interactions (feedback and the operator's action means), on the consistency of the scenarios, and on the future process. After this, an action plan can be proposed to pursue the project.

To evaluate the human-robot interactions, the model should be "interactive", i.e. it can be used to perform simplified tasks. For example, the operator can handle a cardboard model of a robotic arm in order to assess its usability.

The production of the model may be outsourced, but the in-house input data must be taken into account, and the scenarios supplemented and validated by the project team.

Detailed studies and prototype: The aim of the detailed studies is the same as for the basic studies, i.e. to obtain information concerning the technical feasibility linked to the use of a robot, concerning human-robot interactions and concerning the process. However, this stage results in a much more advanced cobotic-system design. To this end, a prototype is designed based on the results of the preliminary analysis and the basic studies, before being tested by the working group (operators, foreman, designers, decision maker, maintenance officers, etc.). In this context, the term prototype refers to a functional (or partially functional) physical model of the future work system. It permits to assess the cobotic system under more realistic conditions than the previous models. The prototype is usually produced by a sup- 
plier in close collaboration with the project's stakeholders, since its development demands specific expertise that is generally not available within the company.

\subsection{Simulations based on the type of cobotic systems}

The type of cobotic system (co-location, co-manipulation or remote operation) chosen within the framework of the industrial project will directly influence the type of things that need to be simulated.

Co-location: The operator and the robot work in the same workspace with no physical separation.

The first aspects to be taken into account when designing a robot that works in the same space as an operator are performance, safety and acceptability. In an industrial context, the system must obviously meet performance requirements, in spite of the safety systems (limited speed and efforts, operator detection, etc.). The safety aspect can be addressed through risk analyzes supported by information from the simulations; this will make it possible to establish the requisite safety measures. It is difficult to assess acceptability by simulating the operators close to robots. On the other hand, they can be placed in a situation where they are in contact with cardboard models, or even immersed in the situation using virtual reality, for example (which makes it possible to incorporate the behavior of the robot) (Weistroffer, et al., 2014), or even using real robots (although this is more demanding in terms of resources and safety).

Simulation also makes it possible to analyze other important points in an industrial project, such as flows (inputs and outputs) and integration of the system in the current workshop.

Co-manipulation: The operator manipulates the robot directly. There are several types of co-manipulation: the operator can manipulate the robot's tool, the operator can manipulate several parts of the robot, or the operator can wear the robot (exoskeleton), which is attached to the operator at several different points.

In addition to the aspects addressed in the previous paragraph, for comanipulation, it is important to simulate the physical contact between the operator and the robot, for example by evaluating efforts and postures (Maurice, et al., 2014). To do this, passive models are often used to validate the structure and bulk of these systems. It is also possible to directly use cobots (robots specially designed and manufactured to interact with humans), which ensure safe human-robot contact.

Teleoperation: The operator interacts with the robot remotely.

As regards remote operation, the safety and physical contact aspects only need to be taken into account for transitory or failure modes. On the other hand, since operators work at distance, they must have enough information to have an adequate overview of the situation (for example, what visual information should the operator 
T. Moulières-Seban, D. Bitonneau, J.-F. Thibault, J.-M. Salotti, B. Claverie

have?) and the means to act according to the requirements. In this way, the level of autonomy can be adjusted according to the situation in order to achieve optimum performance, switching from one of the following modes to another (Kaber, et al., 2000): complete autonomy, supervisory control (Sheridan, 1992), decision support or manual control for instance.

To simulate this kind of remote interaction, it is possible to build a model/prototype of the information and devices proposed to the operator (screens, indicators, alarms, joystick, haptic device, etc.).

\section{PRACTICAL CASE: INTERACTIVE MODEL OF REMOTE OPERATION}

\subsection{Project context}

The simulation presented was used for an industrial project to design a cobotic system to clean tanks soiled with a pasty, sticky, pyrotechnic product. Following the preliminary analysis and the needs definition, a potential solution was retained, after confirmation of its viability by suppliers with technical and practical experience. The planned system comprised a teleoperated robot (to keep operators far from the pyrotechnic area) which was suspended above the tank. It was attached to a linear axis allowing it to reach every part of the tank, change tools and to be kept clear of the tank in transitory and failure modes. The aim of the simulation was to evaluate the planned solution, particularly the remote supervision and control of the robot.

An interactive digital model was developed using the V-REP robotics simulation software (Rohmer, et a 1., 2013). Five students evaluated a preliminary version of the test, which made it possible to perfect the test before launching the final simulation sessions. Then, ten novices ( 7 female and 3 male employees from the company, with an average age of 34) and eight operators experts in manual tank cleaning (only men, with an average age of 36) participated in the test which lasted 30 minutes.

The aim of the simulation was to evaluate:

- The supervision for the automated part of the cycle (scraping the wall of the tank);

- The feedback about the status of the situation given to the user;

- The control of the simulation activity using a keyboard (accurate but constrained) and a joystick (freer interaction) for scraping the walls.

The secondary objective was to collect hands-on information about the need to train operators to control the robots, and the acceptability of the simulation and the control system. 


\subsection{Test protocol}

Before starting, the subjects filled out a questionnaire and then carried out the test following the operating procedure given to them on paper. They filled in another questionnaire at the end.

During the test, the users could move through the scenario using a graphical user interface and control the robot using a keyboard or a joystick (see Fig. 2).

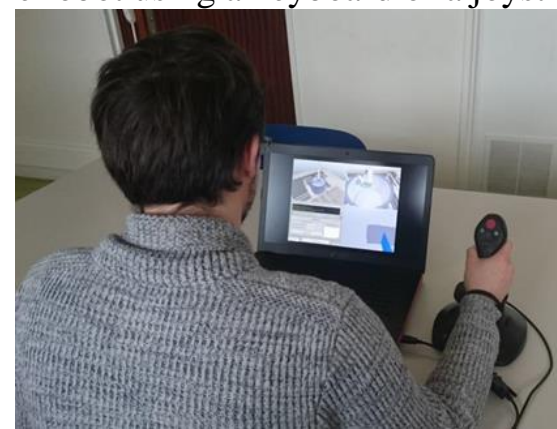

Fig. 2. Photograph of a user performing the test.

The screen display is divided into 4 windows (see Fig. 3):

1. A "tool" view;

2. An intermediate view to keep an eye on the robot's configuration;

3. An overall view of the system;

4. A graphical user interface (presenting data and buttons).

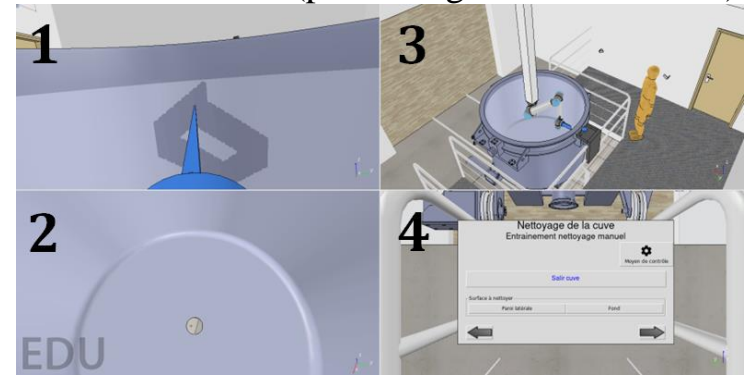

Fig. 3. Screen display during the User test.

A partial cleaning scenario was implemented. It included part of an automated supervised cycle, then a free training period to get used to the manual control (to reduce the learning effect), and finally a time-controlled session that involved cleaning several soiled areas with the joystick and the keyboard. 


\subsection{Results}

In this part, the "keyboard control" and "joystick control" conditions are abbreviated as $\mathrm{KC}$ and $\mathrm{JC}$.

The results of the novices and operators were analyzed together since the oneway ANOVA tests showed that the duration of the task was the same for the two population groups for $\mathrm{KC}(\mathrm{F}=0.01 ; \mathrm{p}=0.925)$ and $\mathrm{JC}(\mathrm{F}=0.14 ; \mathrm{p}=0.716)$.

Supervision of an automated cycle: The supervision of the automated cycle was evaluated using a questionnaire (proposing Likert scales with 5 levels), the results of which are presented in Fig. 4. Overall, the users were satisfied with the supervision of the automated cycle (average of $92.5 \%$ satisfaction as regards the ease of the task, and an average of $77.5 \%$ satisfaction regarding the positioning of the cameras).

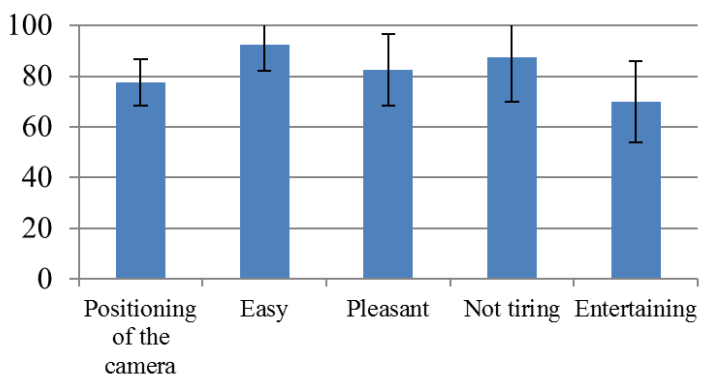

Fig. 4. Bar graph of satisfaction (\%) concerning the supervision of the automated cycle.

Control using the keyboard and joystick: To measure KC and JC, we used two approaches: measurement of performance (cleaning time) and a questionnaire (proposing Likert scales with 5 levels). The main findings are presented Fig. 5 and Fig. 6.

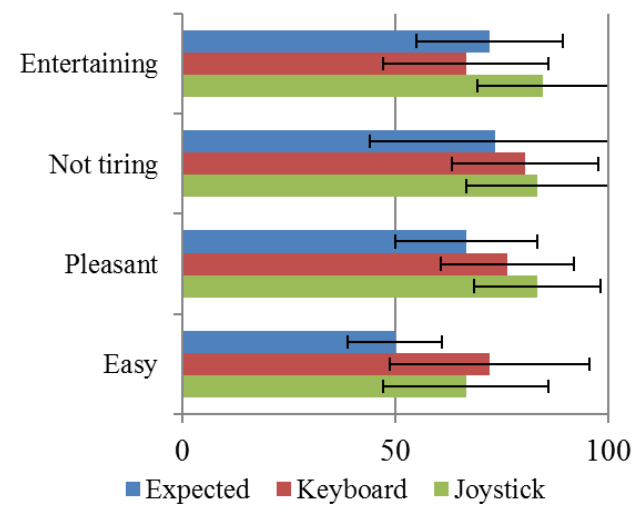

Fig. 5. Bar graph of Satisfaction (\%) concerning KC and JC, compared with users' expectations. 
The Wilcoxon test confirms that $\mathrm{JC}$ is significantly more distracting than $\mathrm{KC}$ ( $\mathrm{W}=41 ; \mathrm{p}=0.038$ ), and that the two means of interaction are easy to use (W=23; $\mathrm{p}=0.48)$.

Moreover, the users generally found $\mathrm{KC}$ and $\mathrm{JC}$ easier than they imagined before carrying out the test (average of $69 \%$ user satisfaction for KC and JC combined, compared with the expected rate of 50\%).

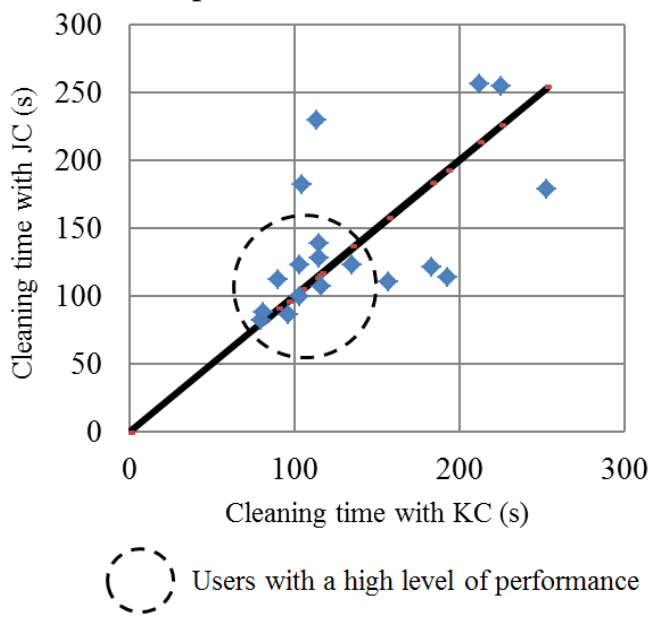

Figure 6: Duration of KC and JC for each user in relation to "KC duration = JC duration" represented by the straight line.

The difference between the performance for $\mathrm{KC}$ and JC follows a normal law, verified by the Shapiro Wilk test concerning normality of the difference $(p>0.1)$. The test for paired data showed no significant difference between the performance with the keyboard and the joystick $(T=-0.22 ; \mathrm{p}=0.830)$. From a qualitative viewpoint, it should nonetheless be noted that a group of 10 users was more efficient than the others with the two control methods.

\subsection{Dissussion}

The proposed experimental system has several limits in terms of the representativeness of the simulation:

- The cleaning process was simulated in a very succinct way; the emphasis was placed on the robot's movements and the interactions;

- The fluidity of the robot's movements during the interactions does not take into account all the robot's parameters (for example its inertia, which can alter the interaction);

- The users were aware the robot was virtual.

Furthermore, not all the work situations were simulated. Indeed, only two situations (supervised and teleoperated scraping) were tested, due to the development time required and operator availability. 
T. Moulières-Seban, D. Bitonneau, J.-F. Thibault, J.-M. Salotti, B. Claverie

This simulation was conducted during the basic study phase, so it did not require a greater degree of detail, since all the other situations were discussed with the working group at the same time. The results on supervisory control and teleoperation of the robot fed the next simulations steps. Main results led to the improvement of the cameras' positions, in particular for the tank's bottom, and the choice of the joystick for flexibility reasons.

\section{CONCLUSION}

In this article, we wanted to demonstrate the importance of simulations in cobotic industrial projects.

To illustrate this, we drew on the practical example (described in III) of a simulation implemented during the basic study phase for a remote-operation system. This case study shows how simulation makes it possible to take the following points into consideration very early in the project cycle when designing a cobotic system:

- The workstation constraints, highlighted by analyzing the existing situation;

- The technical constraints, linked to the interaction between the robot and the operators (the future users of the system);

- The findings concerning the means/tools used for the remote supervision and control of the robot, which were used to design the prototype during the next stage of the project.

Moreover, the user tests produced other results (which are difficult to measure):

- The operators were able to provide expert input concerning the process - and thus improve the design - and to further define the needs linked to controlling the robots;

- The operators - who were already included in the previous phases were able to further assimilate the future system, and confirm that it met their requirements as the project progressed.

A prototype is currently being developed based on the described results. It will also be evaluated via simulations involving the future users.

Finally, simulations in industrial cobotic projects play a decisive role in anticipating:

- The feasibility of a cobotic system (a difficult issue, due to the complexity of human-robot interaction and the technical tools involved);

- The system's performance (crucial for industrial requirements);

- Operator safety (in relation to the robot and possibly the process);

- The acceptability of the planned solution with regard to the future work situations;

- The initiation of operator training. 
Consequently, simulations represent a crucial stage in the development of cobotic systems, providing practical input to support the design throughout the project cycle.

\section{LITERATURE}

1. 9241-210, I. (2010). Ergonomics of human-system interaction -- Part 210: Humancentered design for interactive systems.

2. Barcellini, F., Van Belleghem, L., \& Daniellou, F. (2014). Design projects as opportunities for the development of activities. Dans P. Falzon, Constructive ergonomics (pp. 150-163). Boca Raton, FL, USA: CRC Press.

3. Boy, G. (2013). Orchestrating Human-Centered Design. Springer.

4. Claverie, B., Le Blanc, B., \& Fouillat, P. (2013). La Cobotique. Presses univ. de Bordeaux | "Communication \& Organisation », vol. $2 n^{\circ} 44,203-214$.

5. Daniellou, F. (2004). L'ergonomie dans la conduite de projets de conception de systèmes de travail. Dans P. Falzon, Traité d'Ergonomie (pp. 359-373). Paris: PUF.

6. Daniellou, F. (2007a). Simulating future work activity is not only a way of improving workstation design. @ ctivités, 4(2), 84-90.

7. Daniellou, F. (2007b). Des fonctions de la simulation des situations de travail en ergonomie. @ctivités, 4(2), 77-83.

8. Drury, J., Scholtz, J., \& Yanco, H. (2003). Awareness in Human Robot Interactions. Proceedings IEEE Conference on Systems, Man and Cybernetics (pp. 111-119). Washington, D.C., USA: IEEE.

9. Garrigou, A., Thibault, J. F., Jackson, M., \& Mascia, F. (2001). Contributions et démarche de l'ergonomie dans les processus de conception. PISTES, vol. $3 \mathrm{n}^{\circ} 2$.

10. Kaber, D. B., Onal, E., \& Endsley, M. R. (2000). Design of Automation for Telerobots and the Effect on Performance, Operator Situation Awareness, and Subjective Workload. (J. W. Sons, Éd.) Human Factors and Ergonomics in Manufacturing, 10(4), 409-430.

11. Maurice, P., Schlehuber, P., Padois, V., Bidaud, P., \& Measson, Y. (2014). Automatic selection of ergonomic indicators for the design of collaborative robots. IEEE-RAS International Conference on Humanoid Robots. Madrid, Spain.

12. Moulières-Seban, T., Bitonneau, D., Salotti, J., Thibault, J. F., \& Claverie, B. (2016a). Human Factors Issues for the Design of a Cobotic System. International Conference on Applied Human Factors and Ergonomics. Orlando, FL, USA.

13. Moulières-Seban, T., Bitonneau, D., Thibault, J. F., Salotti, J., \& Claverie, B. (2016b). La Cobotique : un domaine pluridisciplinaire émergent utile à l'ergonome. Congrès de la Société d'Ergonomie de Langue Française.

14. Nielsen, J., \& Molich, R. (1990). Heuristic evaluation of user interfaces. ACM CHI'90. Seattle, WA.

15. Olsen, D., \& Goodrich, M. (2003). Metrics for Evaluating Human-Robot Interaction. Performance Metrics for Intelligent Systems Workshop. NIST. 
T. Moulières-Seban, D. Bitonneau, J.-F. Thibault, J.-M. Salotti, B. Claverie

16. Rohmer, E., Singh, P., \& Freese, M. (2013). V-REP: a Versatile and Scalable Robot Simulation Framework. IEEE International Conference on Intellignet Robots and Systems. Tokyo.

17. Scapin, D., \& Bastien, J. (1997). Ergonomic criteria for evaluating the ergonomic quality of interactive systems. Behaviour and Information Technology, 16(4), 220-231.

18. Scholtz, J. (2002). Theory and Evaluation of Human Robot Interactions. Hawaii International Conference on System Sciences.

19. Sheridan, T. (1992). Telerobotics, Automation, and Human Supervisory Control. MIT Press.

20. Thibault, J. F. (1998). Instrumenter les simulations. Performances $n^{\circ} 97,14-22$.

21. Weistroffer, V., Paljic, A., Fuch, P., Hugues, O., Chodacki, J., Ligot, P., \& Morais, A. (2014). Assessing the Acceptability of Human-Robot Co-Presence on Assembly Lines. IEEE Internatoinal Symposium on Robot and Human Interactive Communication. Edinburg, Scotland, UK. 